\title{
Exploring Teacher Induction: Collaborative Self-Studies across Institutions
}

\author{
${ }^{1}$ Ontario College of Teachers, Canada \\ ${ }^{2}$ Brock University, Canada \\ Correspondence: Déirdre Smith, Ontario College of Teachers, Canada
}

Déirdre Smith ${ }^{1}$, Joe Engemann ${ }^{2}$

Received: January 6, 2015

Accepted: January 23, 2015 Online Published: April 20, 2015

doi:10.11114/jets.v3i3.773

URL: http://dx.doi.org/10.11114/jets.v3i3.773

\begin{abstract}
Educators from eight institutions engaged in collaborative self-studies of their own practices to gain deeper insight into the significance of narrative-based writing for supporting the process of teacher induction. A series of teacher induction institutes based on narrative writing processes provided the context for critical exploration of the lived experiences of both beginning and mentor teachers. These institutes were key components of a tri-level teacher induction partnership between a provincial organization, a faculty of education and six district school boards. The significance of this multi-tiered teacher induction project for initial teacher induction, teacher education and for collaborative self-studies across institutions is explored in this inquiry.
\end{abstract}

Keywords: teacher induction, collaborative self-studies, narrative-based professional learning, reflective practice, institutional partnerships

\section{Introduction}

The focus of this professional learning story is the collaborative inquiry processes that were employed to explore teacher induction. Processes that honour the lived experiences of teachers were employed within this inquiry project. Beginning and mentor teachers from six different school boards engaged in various narrative-based professional learning processes to inquire into their own practice and enhance their individual and collective professional insights and actions. This story of professional learning through self-study began when eight different organizations decided to partner together to explore teacher induction through simultaneous narrative-based self-studies (Figure 1).

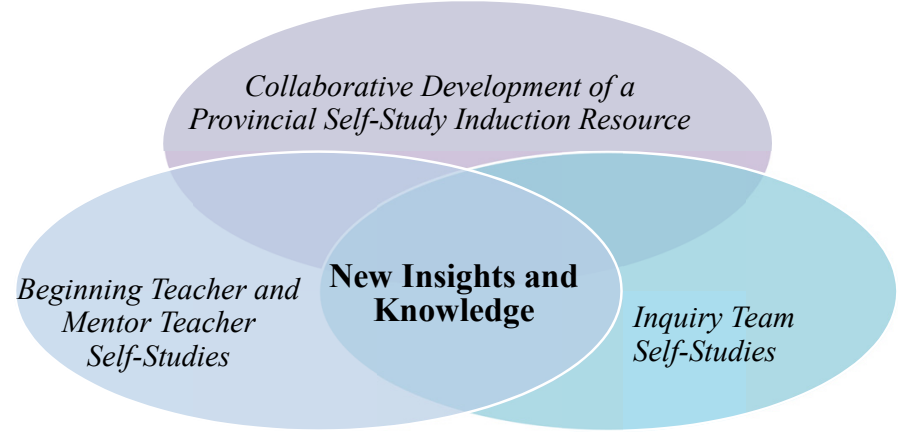

Figure 1. Simultaneous Self-Studies

The main characters in this story include twenty teachers new to the profession, twenty experienced mentor teachers and five members of an inquiry team representing a faculty of education and self-regulatory body for the teaching profession. The teachers self-identified through their respective school boards to be involved in an inquiry project into their lived experiences based on the following criteria:

-Beginning teachers had between one to three years of teaching experience and were currently engaged in a mentoring relationship with a mentor colleague

-Mentor teachers had a minimum of three years experience serving as a mentor colleague

To help enable the beginning teachers to freely and openly discuss their transition into the profession without feeling 
influenced by the presence of their own individual mentor colleague, none of their actual mentors were involved. The teachers represented three elementary school divisions (primary, junior, and intermediate) and were from diverse school contexts.

The beginning teachers, mentors and members of the inquiry team, constructed an innovative plot line in this project that would enable simultaneous self-studies. The collaborative creation of a provincial inquiry-based induction resource (Cherubini et al, 2008), informed by the self-studies experiences of the beginning and mentor teachers, was a key outcome of this inquiry project.

The narrative-based professional learning process that was constructed to support the self-studies involved four dimensions: experience, reflection, analysis and synthesis (Figure 2). These four dimensions supported individual and collegial investigations into professional practice. Deep examinations of practice fostered enhancements in professional knowledge, skills, beliefs, understandings, practices and perspectives.

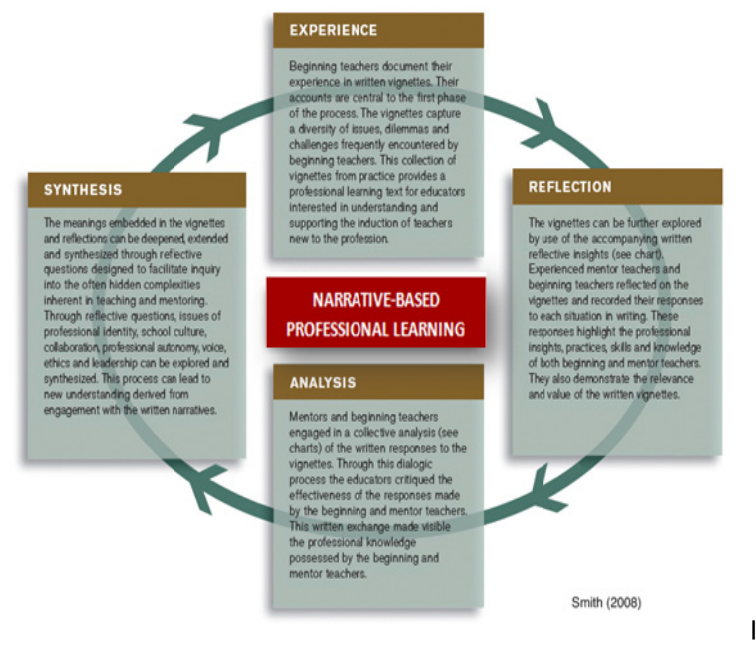

Figure 2. Narrative-based Professional Learning Process

\section{Reflective Writing}

Studying professional practice through the reflective writing produced by beginning and mentor teachers provided insight into teacher development and leadership formation. Written public accounts of individual professional practice enabled the lived experiences (Van Manen, 1990; Dilthey, 2010) of educators to become visible and accessible. These written records of professional practice allowed educators to study their own practice and to enter into and learn from the experiences of colleagues. Written narratives can be powerful relevant professional learning sources for self-study by individual educators, policy developers and the collective teaching profession.

The narratives developed by beginning teachers revealed the issues, challenges and tensions that they were experiencing during their transition to the profession. These experiences required great focus and energy from the beginning teachers as well as being sources of considerable stress. These experiences focused on the following recurring themes,

- responding to the complex needs of individual students

- differentiating instruction

- understanding student behaviour

- reluctance in asking for help and support

- teaching combined grades

- assessing and reporting student progress

- teaching with limited resources

Areas that often immobilized some of the new teachers included fear of being perceived as incompetent; non-acceptance by colleagues; challenges made by parents; and deep feelings of inadequacy. The following vignettes by beginning teachers reveal feelings of despair, fear, exclusion and lack of efficacy,

I was still very uncertain about what I was doing but I was too afraid to ask. I asked myself: "Do the other teachers think I am incompetent? If I ask the wrong question will they wonder how I ever got this job?" I had so many questions but I felt like I had no one to ask. So, I continued to suffer in silence, asking for no help or advice. (Ontario College of Teachers, 
2007, p.39)

Another beginning teacher's reflections convey feelings of exclusion and fear associated with collegial relationships,

I looked on with envy, hoping that I would be included in their gathering one day. "Are they talking about me?" I wondered, feeling paranoid. I could have just wandered over to their secret meeting, but the thought scared me to death. (Ontario College of Teachers, 2015, p.42)

A lack of efficacy is evident in the following scenario depicting an interaction between a parent and beginning teacher,

She didn't give me a chance to finish. Mrs. White went into a rage. "DON'T PATRONIZE ME!" She shrilled. I don't remember what else she said as I stood silently in shock. She yelled at me for what seemed like minutes. All I could think about was who had heard or witnessed this? (Ontario College of Teachers, 2015, p.46)

The written vignettes of practice illuminate the inner world and thinking of new teachers and invite reflection by all those who support the transition of these teachers into the profession. The following vignette reveals the tension, issues and perspectives of one beginning teacher during her initial induction into the teaching profession:

The next 72 hours were a complete blur. I lived and breathed my classroom. How was I supposed to do this? How was I supposed to get my room ready in time for my students? Read the curriculum? Find resources? Make dinner? Plan lessons? ... And the list goes on...an overwhelming sense of "uh oh" hit me and I remember feeling totally paralyzed. (Ontario College of Teachers, 2015, p.43)

The thinking, dispositions, and practices of teacher leaders are elucidated in the following reflections written by two experienced mentor teachers in response to the above written vignette authored by a beginning teacher. These reflections illuminate the orientations of mentors toward supporting beginning teachers. The first mentor teacher explains how she would respond to the experience of the beginning teacher in this vignette by stating:

I would explain that it takes time to build up resources and materials. You cannot expect to have everything you need at the beginning of the year. I would break down the basics and perhaps provide a diagram of what classroom set-ups could look like. Encourage him/her to focus on one task and not think too big; take it one day at a time. Encourage visitations to other classrooms in the school to gain insight and ideas. Encourage him/her by saying every teacher feels this way during this time of year (Ontario College of Teachers, 2015, p.78). A second mentor teacher shares her suggestions for supporting the beginning teacher by explaining.

Tell them everyone feels this way and usually more than once in a year. Seating and set-up are important and should cause stress - it is a sign of a good teacher. Then I would share my room if they wanted to look at it. I would discuss my process and my thinking related to what I did (rows vs. groups, etc). I would take them for a walk to other classes - get a chance to introduce them to other teachers and say we are just here to have a look at class set-up. Once done, I would talk about what they wanted, what their teaching style was and how they would like to start (Ontario College of Teachers, 2015, p.78).

The mentor's reflections make visible the approaches, beliefs and dispositions of teachers. These vignettes of experience and accompanying reflective responses by mentors can be used to enhance individual and collective practices related to the induction of teachers new to the profession and to enhance the thinking and actions of experienced mentor teacher leaders.

\section{Informing Our Collaborative Work}

The conceptualization of our collaborative work was informed by a shared belief that the lived practices and experiences (Van Manen, 1990, Dilthey, 1985) of teachers are valuable sources of wisdom and knowledge that can be mined to improve individual, collective and institutional professional practice.

To support this belief, the theoretical framework for this inquiry was rooted in the traditions of self-study (Loughran, 2002, 2004; LaBoskey, 2007; Russell \& Loughran, 2007; Samaras, 2011) and narrative (Bruner, 1986; Ricouer, 1988; Smith, 2010; Witherell \& Noddings, 1991; Clandinin, 2007). Teacher knowledge is both personal and professional (Connelly \& Clandinin, 1988; Cole \& Knowles, 2000; Smith, 2010). Teachers store their knowledge in narratives (Doyle, 1990) and appear to feel comfortable sharing those stories (Jenlink \& Kinnucan-Welsch, 2001).

The project team recognized self-study as a relevant theoretical framework for developing, implementing and analyzing the teacher induction institute. Self-study allows for a critical examination into educator actions, assumptions and teaching contexts (Russell \& Loughran, 2007). Professional knowledge gained through this process can be applied to one's teaching practice (Samaras, 2002). Self-study also makes visible the reflection, experience and knowledge of educators (Loughran \& Northfield, 1998).

Self-study using narrative professional learning processes was the chosen methodology because it holds the potential for individual, institutional and collective gains (Korthagen, 2004) and because "qualitative research help[s] to open 
educational research to questions of meaning, perspective, ownership and purpose"(Lampert, 2000, p.88). Self-study also enables understanding and insights gained through localized investigations into practice to extend to the broader educational community (Grierson, 2010, Bullogh \& Pinnegar, 2001, Loughran, 2002). As Loughran reminds, "self-studies attempt to speak to individuals, groups, programs and institutions (Loughran, 2002, p. 244). Cochran-Smith and Lytle (1999) view self-study as more rigorous than reflection and describe it as a form of teacher research involving "systemic, intentional, and self-critical inquiry about one's work" (p. 22). Exploration through self-study, supports teachers in developing deeper understanding of their practice, using their own voices and experiences to establish their moral stance to teaching (Bullough \& Pinnegar, 2004).

Hoban (2004) identified that one of the critical elements of self-study is the sharing of professional insights with others and, in so doing, being able to articulate a public theory. The public theory being assessed and illuminated becomes a collective agreed upon theory regarding teaching. Self-study makes public the practice of professional reflection that involves a process of thinking, refining, reframing and developing actions.

Self-study leads to the creation of theories of practice that reside outside the individual (Loughran \& Northfield, 1998) and is based on systematic inquiry into the practices and beliefs of the individual. Making these beliefs, insights and understandings public contributes to the construction of collective professional knowledge (Hoban, 2004). Commitment to making public, the personal professional experiences of educators for the purpose of enhancing collective professional knowledge and practice, served as a key motivator for the involvement of individual educators in the process of sharing their teaching through written narrative-based processes. The educators involved in this project indicated a desire to enhance their own professional practice and to contribute to a public provincial resource (Cherubini et al., 2008) that would support the teaching profession. In many ways, this project could be understood as a form of collective or collaborative self-studies (Samaras \& Freese, 2006; Kitchen, Ciuffetelli Parker, \& Gallagher, 2008).

\section{Interpreting the Self-study Experiences}

Written cases, vignettes, commentaries, feedback forms, group charts, journals, surveys, focus group transcripts and poetry comprised the data sources that were collected and analyzed throughout the project. A collaborative data analysis process was created and employed by the inquiry team.

Several layers of analysis were necessary to achieve a comprehensive understanding of the essence of the lived experiences of the beginning teachers and mentor teachers that emerged in the multiple data sets. The analysis process included multiple readings and joint reviews of the following dimensions of each data source: language, concepts, content, genre, structure, tensions and meaning. Team members first individually and then collaboratively coded, categorized and discussed each data source.

Themes were identified from the narrative data sources and then used as conceptual organizers for the development of a provincial teacher education curriculum and pedagogical resource kit using the narrative writing of the participants. The construction of inquiry-based professional learning processes based on the writing of participants provided an additional analytical lens for exploring participants' written lived experiences.

\subsection{Insights for Professional Practice}

In this project, the collaborative self-studies of beginning teachers, mentors, teacher educators and policy developers led to increased insights and understandings related to,

- Ethical Standards for the Teaching Profession (Ontario College of Teachers, 2006b)

- Standards of Practice for the Teaching Profession (Ontario College of Teachers, 2006b)

- cognitive frames employed by beginning teachers and mentors to interpret their experiences

- effective practices for supporting beginning teachers and mentor teachers

- institutional partnerships for large scale policy implementation.

- privileging the lived experience of educators as the core elements of a provincial induction resource kit entitled, Learning from Experience (Cherubini et al., 2008)

This resource has been made available to 72 English language and French language school boards, faculties of educations, in-service teacher education programs and leadership development courses in Ontario.

\subsection{Beginning Teacher Experiences and Insights}

The written narratives revealed that beginning teachers were dealing with issues related to isolation, inadequacy, lack of confidence, self-doubt, pedagogical challenges, adapting instruction, indecisiveness, balancing expectations and feeling overwhelmed. The words communicated by these beginning teachers helped to illuminate their cognitive frames, thinking and resulting action. The written narratives and related discussions also illustrated the integrated nature of the issues, dilemmas and tensions encountered by these new educators. The multiple ways these challenges permeated and often 
consumed the thinking, perspectives and judgments of beginning teachers was clearly revealed in their written narratives.

The mentor discussions and reflective commentaries enabled the beginning teachers to gain deeper awareness and insight into their own thoughts, feelings, concerns and anxieties. This insight and understanding shed considerable light into the forms of cognitive, emotional and practical support that these educators required and needed to seek out.

The beginning teachers indicated that the narrative professional learning experiences enhanced their sense of efficacy, connection, and professional judgment. They also attributed the narrative processes for helping them to explore and adapt their approaches to framing and interpreting situations. The beginning teachers also identified an increased sense of empowerment as an outcome of the inquiry project.

Most importantly, the beginning teachers indicated that the induction institutes provided them with the time, space, tools and safety to openly unveil their inner thoughts and feelings. By exploring and studying their own professional thinking and practice they were able to gain deep insights, perspectives and knowledge that they believed would inform and enhance their teaching.

\subsection{Mentor Experiences and Insights}

Responding to beginning teacher's experiences through writing reflective commentaries and engaging in discussions enabled the mentors to acquire deeper awareness and insight into the thoughts, feelings, concerns and anxieties of beginning teachers. This new insight and understanding shed considerable light into more effective forms of cognitive, emotional and practical support that mentors might offer to novices entering the teaching profession.

The mentors acknowledged the importance of being open to receiving feedback from beginning teachers and were able to reflect on, analyze and begin to make adaptations to their own thinking and actions as a result of this input. Becoming more conscious of one's own personal beliefs and professional practices related to supporting beginning teachers were common themes identified among the mentors. These teacher educators also recognized the importance of developing more ethical stances that enabled them critically analyze system practices associated with induction. As one teacher educator explained,

All teachers need confirmation, feedback, and guidance in order to feel appreciated, and also to grow as learners and education. I need be more conscious of how I support beginning teachers and to ensure the school support systems do not further overwhelm our new teachers. (Ontario College of Teachers, 2015, p. 197)

Developing and extending the skill of perspective taking was an important leadership skill that many mentors came to understand was essential in helping them to think differently. A mentor teacher emphasized this by stating, "Exposure to a wide variety of thoughts and ideas helped me to reflect on and change my own ways of thinking" (Ontario College of Teachers, 2015, p. 189).

The mentor teachers also explicitly identified the relevance of the ethical standards or standards of practice for the teaching profession (Ontario College of Teachers, 2006a, 2006c) as important guiding frameworks for them as teacher leaders. This is highlighted by the following reflection by a mentor teacher,

For me as a mentor, I believe that open and honest dialogue with new teachers, is in fact, the living out of the Ethical Standards for the Teaching Profession in action. (Ontario College of Teachers, 2015, p. 193)

All the teachers identified that the ethical standards and standards of practice served as core practical lenses for critically reflecting on their professional practice.

\subsection{Inquiry Team Insights and Experiences}

Engagement in a self-study of our own practices was essential to the success of this collaborative tri-level project. It also fostered the advancement of our own individual professional practices as he inquiry team. As facilitators of this project, we explored both our individual and collective practice. This inquiry revealed important insights regarding the value of the self-study paradigm beyond individual practitioner practice. The inquiry team gained deeper insight into the significance of tri-level partnerships and the institutional merit of a collaborative stance towards implementation of provincial teacher education policy (standards). The self-study experience invited team members to inquire into their roles as facilitators, explore values and practices associated with beginning teachers, mentor leaders and collaborative partnerships; reflect on their responses to conflict and tension that emerged within the inquiry team; and to explore how the standards are lived out in their current roles as teacher educators and policy developers.

\section{Insights for Partnerships}

\subsection{Tri-Level Partnerships}

Tri-level partnerships can be extremely powerful and effective for implementing teacher education policy documents such as the ethical standards and standards of practice for the teaching profession in Ontario. For a provincial policy developer, 
this partnership opened the doors to the lived practices of teachers and teacher educators. The relationships fostered in the partnership enabled the staff of the provincial self-regulatory body for the teaching profession to walk alongside practitioners and teacher educators within the world of practice and help support the meaningful and relevant integration of the standards for teachers and teacher educators. This project re-affirmed the importance of policy developers fostering authentic and trusting partnerships. This partnership fostered shared ownership and commitment to the implementation of policies related to teacher education and the teaching profession. The partnership also encouraged the institutions to explicitly associate deeper relevance and meaning to policies.

\subsection{Institutional Influences \& Culture}

The different institutional cultures, agendas and stances of each organization significantly influenced this joint project. These influences needed to be continually reflect upon, acknowledged and negotiated throughout the project.

The different and complex institutional cultures contributed additional dimensions to our project partnership. The institutional culture of the faculty of education, the district school boards and provincial organization were extremely diverse and at times disparate. The purpose or mission of each organization was also very distinct. These differences led to various lenses having to be employed in guiding team decisions and actions. For instance, political, educative and ethical lenses were frequently layered onto our discussions. Team members needed to be aware of the unique mandates, priorities, processes and cultures of each individual institution while at the same time working towards shared goals.

\subsection{Time \& Collaboration}

Our experience as members of the inquiry team and facilitators of the project also revealed the tremendous amount of time, patience, negotiation and communication that are necessary and integral components of a tri-level partnership. Fostering a tri-level partnership process takes time, trust and belief that joint institutional efforts will result in gains for the profession and the public that could never be achieved solely by one institution. Joe's journal reflection illustrates the importance of partners from different organizations respecting and understanding the various institutional influences that can impact a partnership. He also highlights the importance of communication and honest expression of individual expectations,

When two or more people come together for collaborative work, it is most important, I believe, that each person openly express his or her personal expectations for and from the work. This is particularly important when such collaboration happens across institutions. There are often unstated yet powerful institution-specific forces that affect and limit what may be undertaken as research and presented for dissemination. (Journal entry, Joe)

\subsection{Partnership Agreement}

A written partnership agreement was developed at the beginning of the project, which explicitly clarified the project intent, joint work, outcomes, commitments and the responsibilities of each institution involved in the partnership. This agreement surfaced as an essential resource during the 18-month joint project. On many occasions, the agreement helped guide actions, provide answers to questions and resolve conflicts that emerged.

The questions that emerged illuminated the thinking of team members related to fundamental concepts: partnership accountability, shared authorship, responsibility for research dissemination, consequences for actions, philosophies of teaching and learning, joint funding, and ethical obligations. Joe's journal reflection revealed the questions he was contemplating,

What should a multi-institutional partnership agreement contain and how accountable should those participating in the agreement be? What should be the consequences of a failure of accountability by any partners? How should the collaborators from multiple institutions share funding, authorship, and responsibility for dissemination? What are the ethical obligations for sharing information that surfaces during the project that could help to enhance and inform institutional knowledge and practice? (Journal Entry, Joe)

The agreement was particularly useful when issues surfaced at the institutional level regarding the scope of the project, timelines and institutional commitments. Déirdre's journal entry conveys the importance of the partnership agreement for the shared work of the team,

A written research partnership agreement is a necessity when more than one institution is involved in a joint project. It is a helpful resource to have in place when you have a large group of team members or when a project spans over a significant amount of time. The partnership agreement in this project served as a clarifying tool. It also provided clear direction and offered explicit affirmation at the end of the project when all expectations were achieved (Journal entry, Déirdre).

\subsection{Voice \& Authorship}

Issues related to voice and authorship emerged frequently among the inquiry team. The different perspectives related to 
these two concepts created considerable tension among our inquiry team as facilitators of the project. These issues illuminated differences in values, ethical stances and understandings related to collaborative practice. The partnership agreement explicitly identified the original agreements of the team related to these concepts.

Resolution of the issues required considerable lengthy discussions among the inquiry team regarding the following:

- individual perspectives and voice

- potential and real impacts of inquiry team member's actions on the project

- equitable and inclusive contributions from all members

- collaborative practices.

The partnership agreement helped to re-ground the team in the collective objectives of the project and to address perceptions that surfaced related to perceived individual self-interest. It helped move the project forward.

\subsection{Conflict}

Initially, when conflict and tension emerged among the inquiry team all team members did not deal it with in the most effective manner. A lack of sensitivity, openness and transparency created additional conflict and tension for our team. The written reflections, interpretations and representations that surfaced in some member's individual research papers contributed to significant additional conflict and strain for the inquiry team members. Over time, the team attempted to deal with issues and conflict more effectively through engaging in additional dialogue and instituting structured debriefing sessions. The debriefing sessions and partnership agreement were very useful in helping the team respond to and resolve conflict and tension. The team did remain divided on a number of issues such as what constituted the common good and what actions were deemed to reflect self-interest.

\subsection{Direct and Open Communication}

The central importance of direct and open communication for the success of any team cannot be overly emphasized. Tension, disagreement and conflicting perspectives often emerged within our group debriefing and planning sessions. Issues related to voice, shared leadership, mutual respect, honest communication and ethical practice continued to surface throughout the project. These tensions required considerable critical exploration and discussion.

Communication is an essential factor for tri-level partnerships. Joe, a teacher educator and member of the inquiry team, was a key catalyst for facilitating open communication within our group. He consistently attempted to ensure issues were addressed. The following excerpt from his journal illustrates his thinking related to communication,

Direct communication was a real strength of mine, as one of the members of the Faculty of Education. I frequently was the first person to name an issue and to encourage the group to deal with it through dialogue. I encourage open discussion among all members of any research team of which I am a part, expecting that we speak candidly about our ideas and any issues that have arisen, and that we try to gain consensus without negative emotions getting in the way (Journal Reflection, Joe).

Joe recognized the impact of his communication skills upon the team's ability to deal with sensitive issues of power, authority, representation and leadership. His openness to identify issues and engage in dialogue helped the team address many of the implicit tensions that were inherent within the joint sessions. His tenacity prevented members from avoiding issues. The tensions and issues that emerged for our team invited our members to reflect upon their own philosophies and beliefs related to collaboration, voice and ethics. These were not always comfortable conversations.

\subsection{Experiencing a New Paradigm}

Joe was also very skeptical about the team's inclination to embrace the self-study paradigm. He had similar reservations regarding narrative and case approaches. His uncertainty regarding self-study methods frequently surfaced as invitations for in-depth team discussions. His perspectives continually challenged our team. His questions compelled us to reflect more intensely on self-study, narrative and case approaches. We were frequently invited to articulate our thinking and assumptions as a result of his ongoing inquiries regarding the integrity and relevance of this methodology.

Collegial observation, reflection and critique accompanied each institute experience. Sharing our observations, reflections and engaging in critical analysis helped our team to more effectively respond to Joe's ongoing uncertainty and reservations regarding self-study as a research process.

Joe's reflections on his experience with a new research paradigm illustrated the trust he had in his colleagues and their belief in self-study. This trust enabled him to take risks and attempt new forms of reflective practice. His commitment to engaging in continual formal reflection on his practice is evident in the following journal entry,

Self-study has been a new experience for me. There was also a commitment to reflect on our own work as a team. I have always tried to review my practice as a teacher and a researcher, but in very informal ways (for example, making notes on 
my lesson plans, lecture notes, and research field notes), but I cannot say that I have engaged in such formalized reflective practice as I did in this project. (Journal entry, Joe)

\subsection{New Learnings}

The synergy, multiple perspectives, and diverse philosophies held by team members helped propel this innovative project forward. Our reflections and discussions throughout the project revealed that flexibility, intuition, negotiation skills, communication abilities and commitment to collaboration were important factors in helping the project continue to move forward. These dispositions also helped us achieve considerable success regardless of the challenges, tensions and issues that emerged throughout the project.

In addition, the written partnership agreement and the narrative-based professional learning model (Figure 2) became core processes and catalysts for also advancing the project. Déirdre, a policy developer, conveys in her journal reflection how these creative processes were developed as a result of her listening to her intuition and exercising her professional judgment.

The concept of a written partnership agreement emerged for me as I reflected on our struggles to develop shared understanding among our inquiry team. As I observed the group dynamics of our team, I sensed a written document explicitly outlining our understandings and commitments would help us move forward. I went ahead and developed a draft the document and shared it with the team. This document became instrumental in moving the team and the project forward. I did not consciously understand the importance of this document at the project's inception; however, I intuitively believed it was important so I created it. I then worked with each partner institution to ensure their senior leaders supported it. Initially, I was not aware of how important this document would become to the project's movement and success. The narrative-based professional learning process was also created as a result of my intuition. As an inquiry group, we were struggling with how to invite the teachers to engage in forms of self-study that would be relevant, foster critical reflection and could be used by the collective profession. The concept of the narrative-based professional learning framework (Figure 2) was inspired by my intuition and my judgments related to self-directed forms of professional learning. (Journal Reflection, Déirdre)

The significance of listening to forms of intuitive knowledge and then utilizing it to inform professional judgment was reinforced for Déirdre during this inquiry process. Members of the inquiry team also gained increased insight into their own pedagogical knowledge, political acuity, leadership styles, beliefs, ethics, and facilitation skills.

\section{Educational Significance}

This collaborative self-inquiry, which resulted in, the co-creation of an induction resource kit (Cherubini, et al., 2008) provided for individual, institutional and collective (Figure 3) educational gains (Korthagen, 2004).

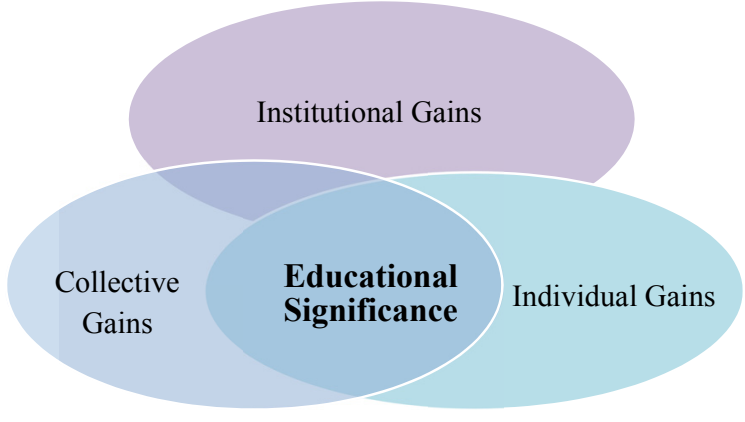

Figure 3. Educational Significance

\subsection{Individual Gains}

The narratives that were developed, discussed and analyzed by the group of beginning teachers and mentor teachers involved in this research project provided rich descriptions (Geertz, 1973) of the types of dilemmas, issues and experiences that may be encountered during initiation into the teaching profession. These written accounts of experience also illustrate the multiple dimensions of teacher leadership embodied by these educators as they negotiated their roles as beginning or mentor teachers.

Facilitating professional inquiry through the use of narrative processes supported beginning teachers in learning to professionally think about, frame and re-frame issues from practice. It also encouraged the use of the language of the profession's standards (Ontario College of Teachers, 2006b) as a shared theoretical lens to discuss issues encountered in practice. As one beginning teacher stated, "The standards and casework provided us with the language required to have a 
professional conversation" (Ontario College of Teachers, 2015, p.14).

The case and vignette process helped prepare these beginning teachers for future representative dilemmas. When these teachers encounter similar dilemmas in practice they will have already thought about and discussed comparable situations in depth. This is professional knowledge that can be drawn upon later when needed. The narrative writing processes also helped connect teachers to one another and to their collective profession. Many of the beginning teachers highlighted this in their feedback. For instance, two participants shared, "We are not alone... and we can survive the 'initial rush' that we encounter" and "I'm not alone. I feel more confident in what I do and in what I know" (Ontario College of Teachers, 2007).

This self-study illuminated the issues encountered by beginning teachers and mentor teachers; highlighted the multiplicity of perspectives held by beginning teachers and teacher mentors; identified the significance of the profession's standards for beginning teachers and mentors; revealed the impact of various narrative processes upon professional practice; illustrated the power of narrative-based professional learning; revealed the professional needs of educators and offered alternative lenses to understand and reframe the experiences of beginning teachers. Engaging beginning teachers and mentors in a dialogic written critique of professional practice enables previously hidden dimensions of practice to be revealed, analyzed and revised. The beginning teachers described the narrative approaches to professional learning that were used in this project as non-judgmental, valuing of their inner wisdom and very liberating.

Narrative-based professional learning processes validate, affirm, connect, support and empower beginning teachers. They help move teachers from feelings of disillusionment and isolation to feelings of hope, confidence and a sense of connectedness to a meaningful profession. Narrative-based professional learning also helps to inform the perspectives and practices of both teacher educators and policy developers related to the complex process of induction into the profession.

Self-study using narrative and case approaches holds the power to rebuild the confidence of beginning teachers, break down feelings of isolation, reinforce positive images of professional identity and enhance professional efficacy. The following reflections by beginning teachers illuminate the value of narrative professional learning processes for induction; "These sessions have had a profound impact on my confidence. I gained new insights into all that a new teacher goes through and realized that I am not alone" (Ontario College of Teachers, 2015, p.92) and "I feel less alone. I have been empowered. The affirmation I received tells me I am on the right track. I have made connections/support networks that did not exist prior to these sessions" (Ontario College of Teachers, 2015, p.92).

The induction resource kit, Learning from Experience: Supporting Beginning Teachers and Mentors (Cherubini et al., 2008), sheds light on the images and assumptions often associated with beginning and mentor teachers. A multiplicity of images of beginning teachers is depicted in this induction resource: leaders, mentors, risk takers, novices and uncertain learners. The written narratives and commentaries in this resource invite reflection upon the assumptions frequently held about the needs of beginning teachers and the forms of support they require.

The practices and perspectives of mentor teachers were significantly enhanced through engagement in this self-study. Narrative processes enabled the actions, suggestions and philosophies of mentor teachers to be made visible thus allowing them to be revisited, critiqued and reconstructed if necessary.

Mentor teachers also identified the value of this self-study project upon their own growing professional knowledge and enhanced ability to support beginning teachers. They supported the use of collaborative professional learning processes involving writing and dialogue by beginning teachers and mentors. These approaches revealed deep insight regarding the thinking, emotions and practices of both beginning teachers and mentors. One mentor teacher explained the value of narrative approaches for induction by stating, "Narrative approaches validate, affirm, connect, support and empower beginning teachers. They help move teachers from feelings of disillusionment and isolation to feelings of hope, confidence and a sense of connectedness to a meaningful profession (Ontario College of Teachers, 2015, p. 92).

Many participants highlighted the usefulness of this project for the ongoing professional learning of mentor teachers. A teacher leader stressed the importance of mentors acquiring insight into induction through the written self-studies of beginning teachers by stating, "The most useful component of the sessions was to read and write responses to the vignettes written by beginning teachers". (Ontario College of Teachers, 2015, p.61) Another teacher leader highlighted the power of narrative-based professional learning by expressing, "I have been too many workshops: the most poignant have been the ones that invite me to reflect on my own practice (p.63).

The inquiry team members also benefited individually from this project. These individual gains identified by the team included increased knowledge and insight regarding our own practices as teacher educators and policy developers. We also gained additional perspectives regarding how we work within the framework of partnerships as both members and representatives of individual institutions. This new information will help inform our individual work related to future educational partnerships. 
The impact and promise of narrative-based professional learning is highlighted in an email received from one of the participants, a beginning teacher, following the last joint session of this project, "What an incredible day I had today. I feel extremely fortunate to be in such excellent company. I feel the future of education has never shone with such exuberance in my heart and mind as it does now" (Personal email).

\subsection{Institutional Gains}

The institutional gains from being involved in this collaborative self-study were multi-fold. The district school boards and faculties of education gained a practical inquiry-based resource kit to use in the enhancement of their induction programs. They also benefited from having a cadre of beginning teachers and mentors who had engaged in this form of narrative professional learning. These individuals can now serve as institutional resources for fostering self-study of individual and collective professional practices within these individual school districts.

This collaborative professional learning project illustrated the value of partnerships for supporting the regulatory body's efforts to assist in the meaningful integration of the profession's ethical and practice standards within initial teacher education. This project holds implications for the future work of the regulatory body related to the ethical standards and initial teacher education. One teacher educator emphasized that the induction institute, "Fundamentally changed how our group will inform teacher candidates about the standards and the role of the Ontario College of Teachers" (Ontario College of Teachers, 2015, p. 69). A mentor teacher shared, "I realized how you can effectively connect the standards to the reality of teaching. Our stories become very good resources for the profession!” (pp. 68-69). Participants also identified several benefits of this project for their individual institutions. These included:

- value of the standards-based case formats for their professional learning

- relevance of practitioner generated resources created from the actual lived practice of beginning and mentor teachers

- new understanding gained regarding the role that joint partnerships can have upon teacher education, professional practice and ultimately the for the public good.

The Faculty of Education's efforts to support the induction of beginning teachers were enhanced as a result of this project. The connection between initial teacher education, induction and continuing teacher education was clearly identified by the participants in this project. The integration of narrative, case methods and vignettes were recommended as important inquiry processes to be integrated within both teacher education and professional learning. All involved also gained a deeper understanding of how the standards can be meaningfully integrated within teacher education.

\subsection{Collective Gains}

This self-study has the potential to have significant impact on the collective teaching profession. The inquiry-based induction resources developed within this joint project were made available throughout the province. This induction kit was forwarded to all Directors of Education, Deans of Education and the Ministry of Education. Several thousand educators and educational institutions have now used this teacher education resource kit provincially, nationally and internationally. A Superintendent, shared his experience in using this kit,

We used the vignette III and VI at our New Teacher Induction Program session. These resources helped to generate some tremendous discussion within the groups. In fact, it was a real challenge to get them to stop talking so that we could move on in the agenda. The feedback from the new teachers and the mentors was very positive. (Personal email).

This collaborative research project also reinforced the importance and relevance of the profession's ethical and practice standards for the induction of beginning teachers, for the role of mentor teachers and for teacher education. The portraits of practice created by the educators can be discussed and critiqued using the shared theoretical lens and language of the standards.

This joint induction partnership confirmed the value of professional inquiry using cases, vignettes and commentaries for initial teacher education, teacher induction and the professional learning of mentor teachers.

\section{Contribution to the Field of Self-study}

This research project contributes to the field of self-study in several ways. It clearly illustrates the potential of self-study research for institutional practice and policy implementation. The power and reach of institutions working together for larger purposes such as the enhancement of teacher induction in the province has been exemplified throughout this initiative. As practitioners, policy developers and teacher educators collaboratively work across institutions towards shared goals related to the teaching profession greater gains are achieved. This form of multi-tiered self-study enables policy makers to gain a depth of understanding regarding the relevance of teacher education policy for practitioners, teacher educators and the public. It also helps to support the implementation of policies through shared ownership, understanding and collective efficacy. 
This project illuminates the promise of collaborative self-study conducted within a team comprised of practitioners, teacher educators and policy makers. Collaborative self-study across institutions enables practitioners to exercise increased leadership, strengthens their voices and enables their wisdom of practice to be acknowledged as valuable contributors to teaching, learning, teacher education and the implementation of provincial policy.

Collaborative self-study holds the power to advance individual and institutional agendas. Institutional self-study partnerships can also have a significant impact on the collective teaching profession due to the reach of each of these institutions. This tri-level research partnership was able to connect with and offer relevance for district school boards, faculties of education and other provincial organizations. Collaborative self-studies across institutions can be a valuable vehicle for providing meaningful feedback for institutions. Information regarding the institutional stance, policies, cultures, ethics, leadership practices and purposes can be garnered from this form of shared critical inquiry. This collaborative selfstudy across institutions invites further exploration in self-study as a research methodology:

-How can collaborative self-study be re-conceptualized to enable it to be more authentically "owned" by practitioners as well as teacher educators?

-How can institutions employ collaborative self-studies to advance institutional agendas and inform institutional culture?

-How can collaborative self-studies across institutions support the democratization of policy development and implementation?

The field of self-study could gain greater acceptance, credibility and influence by being viewed and employed as methodology for both professional practice as well as for the development and implementation of educational policy within collaborative projects across institutions. This would help extend its' present scope, reach and use beyond the individual practice of teacher educators. Collaborative self-study across institutions offers considerable coherence to shared initiatives. It also explicitly illustrates the power of combined institutional implementation efforts over singular institutional attempts. This collaborative methodology has the potential for extending greater impact and influence upon both teacher education policy and professional practice. Collaborative institutional self-studies may also help to cultivate deeper understanding of the shared value and accountability associated with this inquiry method for supporting institutional practices that enable multiple voices and perspectives to enter into the arena of policy implementation. Thus, shifting the dynamics of power and influence towards the institutional embodiment of more equitable, inclusive and emancipatory policies, processes and pedagogies.

\section{References}

Bruner, J. (1986). Actual minds: Possible worlds. Cambridge, MA: Harvard University Press.

Bullough, R. V., \& Pinnegar, S. (2001). Guidelines for quality in autobiographical forms of self-study research. Educational Researcher, 30(3), 13-21. http://dx.doi.org/10.3102/0013189X030003013

Bullough, R. V., \& Pinnegar, S. (2004). Thinking about the thinking about self-study: An analysis of eight chapters. In J. J. Loughran, M. L. Hamilton, V. K. LaBoskey, \& T. Russell (Eds.), International handbook of self-study of teaching and teacher-education practices, 313-342. Dordrecht, the Netherlands: Kluwer. http://dx.doi.org/10.1007/978-1-4020-6545-3_9

Cherubini, L., Smith, D., Goldblatt, P. F., Engemann, J., \& Kitchen, J. (2008). Learning from experience: Supporting beginning teachers and mentors. Toronto, ON: Ontario College of Teachers.

Clandinin, D. J., (2007). Handbook of narrative inquiry: Mapping a methodology. San Francisco, CA: Sage Publications. http://dx.doi.org/10.4135/9781452226552

Cochran, S. M., \& Lytle, S. L. (1999). The teacher research movement: A decade later. Educational Researcher, 28(7), 15-25. http://dx.doi.org/10.3102/0013189X028007015

Cole, A. L., \& Knowles, G. J. (2000). Researching teaching: Exploring teacher development through reflexive inquiry. Boston, MA: Allyn and Bacon.

Connelly, M. F., \& Clandinin, D. J. (1988). Teachers as curriculum planners: Narrative of experience. New York, NY: Teachers College Press.

Dilthey, W. (2010). Wilhelm Dilthey: Selected works, Volume III: The formation of the historical world of the human sciences. R. A. Makkreel, \& F. Rodi (Eds.). Princeton, NJ: Princeton University Press.

Doyle, W. (1990). Case methods in the education of teachers. Teacher Education Quarterly, 17(1), 7-15. http://www.jstor.org/stable/23475063.

Geertz, C. (1973). Thick description: Toward an interpretative theory of culture. C. Geertz, The interpretation of cultures (pp. 3-30). New York, NY: Basic Books. 
Grierson, A. L. (2010). Changing conceptions of effective teacher education: The journey of a novice teacher educator. Studying Teacher Education, 6(1), 3-16. http://dx.doi.org/10.1080/17425961003668898

Hoban, G. (2004). Using information and communication technologies for the self-study of teaching. J. J. Loughran, M. L. Hamilton, V. K. LaBoskey, \& T. Russell (Eds.), International handbook of self-study of teaching and teacher education practices (pp. 1030-1072). London: Kluwer Academic. http://dx.doi.org/10.1007/978-1-4020-6545-3_26

Jenlink, P. M., \& Kinnucan, W. K. (2001). Case stories of facilitating professional development. Teaching and Teacher Education, 17(6), 705-724. http://dx.doi.org/10.1016/S0742-051X(01)00025-7

Kitchen, J., Ciuffetelli, P. D., \& Gallagher, T. (2008). Authentic conversation as faculty development: Establishing a self-study group in an education college. Studying Teacher Education, 4(2), 157-177. http://www.ed.brocku.ca/ tgallagher/includes/SSTEJ_Jan_3.pdf.

Korthagen, F. (2004). In search of the essence of a good teacher: Towards a more holistic approach in teacher education. Teaching and Teacher Education, 20(1), 77-97. http://dx.doi.org/10.1080/17425960802433637

LaBoskey, V. K. (2007). Afterword: Moving the methodology of self-study research and practice forward: Challenges and opportunities. J. J. Loughran, M. L. Hamilton, V. K. LaBoskey, \& T. Russell (Eds.), International handbook of self-study of teaching and teacher education practices, (pp. 1169-1184). London: Kluwer Press.

Lampert, M. (2000). Knowing teaching: The intersection of research on teaching and qualitative research. Harvard Educational Review, 70(1), 86-99.

Loughran, J. J. (2002). Understanding self-study of teacher education practices. J. J. Loughran, \& T. Russell (Eds.), Improving teacher education practices through self-study (pp.239-248). London: RoutledgeFalmer.

Loughran, J. J. (2004). A history and context of self study of teaching and teacher education practices. J. J. Loughran, M. L. Hamilton V. K. Kubler LaBoskey, \& T. Russell (Eds.), International handbook of self-study of teaching and teacher education practices, Part One (pp.7-39). London: Kluwer Academic Publishers. http://dx.doi.org/10.1007/978-1-4020-6545-3

Loughran, J. J., \& Northfield, J. R. (1998). A framework for the development of self-study practice. In M.L. Hamilton (Ed.), Reconceptualizing teacher practice: Self-study in teacher education (pp. 7-18). London: Falmer Press.

Ontario College of Teachers. (2006a). Ethical standards for the teaching profession. Toronto, ON: Author.

Ontario College of Teachers. (2006b). Foundations of professional practice. Toronto, Ontario: Author.

Ontario College of Teachers. (2006c). Standards of practice for the teaching profession. Toronto, ON: Author.

Ontario College of Teachers. (2015). [Induction and Mentoring Project]. Unpublished raw data.

Ricoeur, P. (1988). Time and narrative (K. McLaughlin \& D. Pellauer, Trans.). Chicago, IL: University of Chicago Press. (Original work published 1983). http://dx.doi.org/10.7208/chicago/9780226713533.001.0001

Russell, T., \& Loughran, J. J. (Eds.) (2007). Enacting a pedagogy of teacher education: Values, relationships and practices. London: Routledge.

Samaras, A. P. (2002). Self-study for teacher educators: Crafting a pedagogy for change. New York, NY: Peter Lang Publishing Group.

Samaras, A. P. (2011). Self-study teacher research: Improving your practice through collaborative inquiry. Thousand Oaks, CA: Sage Publications, Inc.

Samaras, A. P., \& Freese, A. R. (2006). Self-study of teaching practices. New York, NY: Peter Lang.

Smith, D. (2008). Narrative inquiry process. Booklet presented at the Ministry of Education Symposium, Toronto, ON.

Smith, D. (2010, April). The power of narrative to inform public policy: Re-conceptualizing a principal's qualification program. Paper presented at the annual meeting of the American Education Research Association Denver, CO.

Van Manen, M. (1990). Researching lived experience. London, ON: University of Western Ontario.

Witherell, C., \& Noddings, N. (Eds.). (1991). Stories lives tell: Narrative and dialogue in education. New York, NY: Teachers College Press.

\section{$(\infty)$ EY}

This work is licensed under a Creative Commons Attribution 3.0 License. 